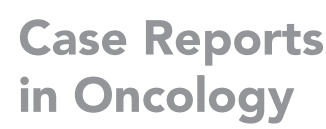

Case Reports

in Oncology

This article is licensed under the Creative Commons Attribution-NonCommercial 4.0 International License

\title{
Iron Deficiency Anemia-Induced Lymphocytopenia in a Young Female
}

\author{
Elabbass A. Abdelmahmuod ${ }^{a}$ Mohamed A. Yassin $^{b}$ \\ aDepartment of Internal Medicine, Hamad Medical Corporation, Doha, Qatar; ${ }^{b}$ Department \\ of Medical Oncology, National Center for Cancer Care and Research, Doha, Qatar
}

\section{Keywords}

Iron deficiency anemia $\cdot$ Leukopenia $\cdot$ Lymphopenia $\cdot$ Anemia

\begin{abstract}
Iron deficiency anemia is the most common type of anemia, and it occurs when the human body does not have enough of the mineral iron (https://www.healthline.com/health/irondeficiency-anemia\#diagnosis). Iron deficiency anemia is caused by blood loss, insufficient dietary intake, or poor absorption of iron from food. Sources of blood loss can include heavy periods, childbirth, uterine fibroids, stomach ulcers, colon cancer, and urinary tract bleeding (https://www.nhlbi.nih.gov/health-topics/iron-deficiency-anemia). Poor absorption of iron from food may occur as a result of an intestinal disorder such as inflammatory bowel disease or celiac disease, or surgery such as a gastric bypass (https://www.who.int/nutrition/topics/ ida/en/). Little is known about the association between iron deficiency anemia and lymphocytopenia. Here, we report on a 17-year-old female who presented with iron deficiency anemia and was found to have lymphopenia. She recovered after having received intravenous iron therapy.

(C) 2020 The Author(s).

Published by S. Karger AG, Basel
\end{abstract}

\section{Introduction}

Iron deficiency anemia (IDA) arises when the balance of iron intake, iron storage, and the body's loss of iron are insufficient to fully support the production of erythrocytes. IDA rarely causes death, but the impact on human health is significant [1]. Symptoms of IDA are related to decreased oxygen delivery to the entire body and may include the following: unexplained fatigue or lack of energy; shortness of breath or chest pain, especially with activity; unex- 
Table 1. Complete blood count upon presentation

\begin{tabular}{|c|c|c|c|c|c|c|}
\hline Group & Detail & Date & Value & Flags & $\begin{array}{l}\text { Normal } \\
\text { range }\end{array}$ & $\begin{array}{l}\text { Comment } \\
\text { Ind }\end{array}$ \\
\hline General hematology & WBC & 03/12/2018 13:20:00 AST & $7.5 \times 10^{3} / \mu \mathrm{L}$ & & $4.0-10.0$ & \\
\hline General hematology & $\mathrm{RBC}$ & 03/12/2018 13:20:00 AST & $4.1 \times 10^{6} / \mu \mathrm{L}$ & & $3.8-4.8$ & \\
\hline General hematology & $\mathrm{Hgb}$ & 03/12/2018 13:20:00 AST & $5.2 \mathrm{~g} / \mathrm{dL}$ & CRIT & $12.0-15.0$ & $\mathrm{Y}$ \\
\hline General hematology & Hct & 03/12/2018 13:20:00 AST & $21.2 \%$ & LOW & $36.0-46.0$ & \\
\hline General hematology & MCV & 03/12/2018 13:20:00 AST & $51.2 \mathrm{fL}$ & LOW & $83.0-101.0$ & \\
\hline General hematology & $\mathrm{MCH}$ & 03/12/2018 13:20:00 AST & $12.6 \mathrm{pg}$ & LOW & $27.0-32.0$ & \\
\hline General hematology & Platelet & 03/12/2018 13:20:00 AST & $302 \times 10^{3} / \mu \mathrm{L}$ & & $150-400$ & \\
\hline General hematology & $\begin{array}{l}\text { Absolute neutrophil } \\
\text { count auto\# (ANC) }\end{array}$ & 03/12/2018 13:20:00 AST & $6.19 \times 10^{3} / \mu \mathrm{L}$ & & $2.00-7.00$ & \\
\hline General hematology & Lymphocyte auto\# & 03/12/2018 13:20:00 AST & $0.74 \times 10^{3} / \mu \mathrm{L}$ & LOW & $1.00-3.00$ & \\
\hline
\end{tabular}

Table 2. Iron profile >> severe iron deficiency anemia

\begin{tabular}{|c|c|c|c|c|c|c|}
\hline Group & Detail & Date & Value & Flags & $\begin{array}{l}\text { Normal } \\
\text { range }\end{array}$ & $\begin{array}{l}\text { Comment } \\
\text { Ind }\end{array}$ \\
\hline Blood chemistry & Iron & 07/08/2019 10:40:00 AST & $5.23 \mu \mathrm{mol} / \mathrm{L}$ & LOW & $5.90-18.30$ & \\
\hline Blood chemistry & TIBC & 07/08/2019 10:40:00 AST & $70 \mu \mathrm{mol} / \mathrm{L}$ & & $45-80$ & \\
\hline Blood chemistry & $\mathrm{Fe} \%$ saturation & 07/08/2019 10:40:00 AST & $7 \%$ & LOW & $15-45$ & \\
\hline Endocrinology & Ferritin & 07/08/2019 10:40:00 AST & $3 \mu \mathrm{g} / \mathrm{L}$ & LOW & $6.0-44.0$ & \\
\hline
\end{tabular}

plained generalized weakness; a rapid heartbeat; headache, especially with activity; craving for ice or clay ("picophagia"); a sore or smooth tongue; and brittle nails or hair loss [2]. According to the WHO, the criterion for anemia is a hemoglobin level $<13 \mathrm{~g} / \mathrm{dL}$ in adult males and $<12 \mathrm{~g} / \mathrm{dL}$ in adult females. As the iron deficiency worsens, both hemoglobin and PCV decline together [3]. The diagnosis of iron deficiency to be confirmed by any one of the following findings in the appropriate clinical setting: serum ferritin $<30 \mathrm{ng} / \mathrm{mL}$; transferrin saturation $<19 \%$, mostly used in patients for whom the ferritin level is thought to be unreliable due to an inflammatory state; or anemia that resolves upon iron administration or absence of stainable iron in the bone marrow (provided that adequate staining controls are performed [4]).

IDA presents with thrombocytosis; however, there rarely is an association between IDA and lymphocytopenia. Here, we would like to shed light on this rare presentation.

\section{Case Presentation}

A 17-year-old female who presented with dizziness and fatigability was found to have severe anemia (hemoglobin $5.2 \mathrm{~g} / \mathrm{dL}$; normal value 12-15). Her menstrual cycle was normal, but she had poor nutrition; she denied other symptoms. On examination, she showed severe pallor, but no hepatosplenomegaly. For her laboratory results, see Tables 1-4.

\section{Peripheral Smear}

Red blood cells showed mild anisopoikilocytosis with few ovalocytes/elliptocytes and occasionally schistocytes. Leukocytes occasionally showed reactive lymphocytes. Monocytes were slightly prominent. Platelets were adequate.

\section{Karger'}


Table 3. Vitamin B12, folate and thyroid function test

\begin{tabular}{|c|c|c|c|c|c|c|}
\hline Group & Detail & Date & Value & Flags & Normal range & Comment \\
\hline Endocrinology & Vit. B12 & 15/09/2019 18:50:00 AST & $250.0 \mathrm{pmol} / \mathrm{L}$ & & $145.0-596.0$ & \\
\hline Endocrinology & Folate & 07/08/2019 10:40:00 AST & $17.74 \mathrm{nmol} / \mathrm{L}$ & $\mathrm{HIGH}$ & $2.70-16.30$ & \\
\hline Endocrinology & TSH & 28/01/2019 08:32:00 AST & $2.260 \mathrm{mIU} / \mathrm{L}$ & & $0.700-3.400$ & Y \\
\hline Endocrinology & $\mathrm{fT}_{4}$ & 28/01/2019 08:32:00 AST & $10.7 \mathrm{pmol} / \mathrm{L}$ & & $7.9-13.6$ & $\mathrm{Y}$ \\
\hline
\end{tabular}

Table 4. Laboratory results after therapy

\begin{tabular}{|c|c|c|c|c|c|c|}
\hline Group & Detail & Date & Value & Flags & $\begin{array}{l}\text { Normal } \\
\text { range }\end{array}$ & $\begin{array}{l}\text { Comment } \\
\text { Ind }\end{array}$ \\
\hline General hematology & $\mathrm{RBC}$ & 07/08/2019 10:40:00 AST & $5.0 \times 10^{6} / \mu \mathrm{L}$ & HIGH & $3.8-4.8$ & \\
\hline General hematology & $\mathrm{RBC}$ & 07/08/2019 10:40:00 AST & $5.2 \times 10^{6} / \mu \mathrm{L}$ & $\mathrm{HIGH}$ & $3.8-4.8$ & \\
\hline General hematology & $\mathrm{Hgb}$ & 07/08/2019 10:40:00 AST & $11.0 \mathrm{~g} / \mathrm{dL}$ & LOW & $12.0-15.0$ & \\
\hline General hematology & Platelet & 07/08/2019 10:40:00 AST & $408 \times 10^{3} / \mu \mathrm{L}$ & $\mathrm{HIGH}$ & $150-400$ & \\
\hline General hematology & Platelet & 07/08/2019 10:40:00 AST & $392 \times 10^{3} / \mu \mathrm{L}$ & & $150-400$ & \\
\hline General hematology & Lymphocyte auto\# & 07/08/2019 10:40:00 AST & $1.41 \times 10^{3} / \mu \mathrm{L}$ & & $1.00-3.00$ & \\
\hline Endocrinology & Ferritin & 07/08/2019 10:40:00 AST & $31.9 \mu \mathrm{g} / \mathrm{L}$ & & $6.0-44.0$ & \\
\hline
\end{tabular}

The patient received IV ferric carboxymaltose (Ferinject) at 1,000 mg in 2 doses. Her symptoms, anemia, and lymphocytopenia dramatically improved after therapy.

\section{Discussion}

Iron plays an essential role in immunosurveillance, because of its growth-promoting and differentiation-inducing properties for immune cells and its interference with cell-mediated immune effector pathways and cytokine activities [5].

IDA is a problem of serious public health significance that impacts mental and physical development, health maintenance, and work performance. It is the most common micronutrient deficiency worldwide. It exceeds $50 \%$ in developing countries and is usually attributed to inadequate nutrition [6]. IDA due to nutritional deficiency is not just a disease of developing countries, but it can also be seen in developed countries. Worldwide, over $40 \%$ of cases of children who have iron deficiency anemia are frequently associated with infections [7].

IDA impairs thyroid metabolism in animals and humans and may negatively affect the growth and development of children. On the other hand, both overt and subclinical hypothyroidism are associated with anemia, and adding iron to thyroxine therapy improves both conditions compared to thyroxine therapy alone. In addition, patients with chronic hemolytic anemia requiring repeated blood transfusion have a high prevalence of hypothalamic-pituitary-thyroid axis disturbances. Both primary hypothyroidism and central hypothyroidism occur in these patients with increasing prevalence with age and severity of the anemia [8]. It appears that all forms of chronic anemia have a negative effect on linear growth during all stages of growth (infancy, childhood, and adolescence). Although infants with chronic IDA may have delayed cognitive, motor, and affective functions [9], the effects on male fertility explored by Soliman et al. [10] in a study showed that correction of IDA with IV iron is associated with significant enhancement of sperm parameters and increased concentrations of serum LH, FSH, and T. These effects on spermatogenesis are reached by an unknown mech- 
anism and suggest a number of pathways that need further human and/or experimental studies. In another study looking for the effects of IDA on glucose metabolism, Soliman et al. [11] suggest that among nondiabetic and diabetic individuals, IDA is associated with higher concentrations of $\mathrm{HbA}_{1 \mathrm{c}}$. Iron replacement therapy decreases $\mathrm{HbA}_{1 \mathrm{c}}$ in both diabetic and nondiabetic individuals. This implies that the iron states must be considered during the interpretation of $\mathrm{HbA}_{1 \mathrm{c}}$ concentrations in diabetic or nondiabetic patients. Early diagnosis and treatment of IDA in diabetic patients can improve their glycemic control and may prevent or delay complications.

Worldwide, over $40 \%$ of children have IDA, frequently associated with infections. Certain cytokines are involved in both immune activation of/response to infection and iron transport/ metabolism. An increased susceptibility to infections has been reported in some IDA patients, the etiology of which is not well known [5].

Iron is required for monocyte/macrophage differentiation, while macrophages require iron as a cofactor for the execution of important antimicrobial effector mechanisms, including the nicotinamide adenine dinucleotide phosphate hydrogen-dependent oxidative burst [12].

Little is known concerning the effect of clinical iron deficiency on cytokines, although it has been reported that in vitro production of cytokines by lymphocytes in iron-deficient patients may be impaired [5] and thus may make people with IDA more susceptible to infections.

\section{Conclusion}

IDA commonly presents with typical signs and symptoms. However, it rarely can present with atypical presentation, lymphocytopenia being one of them. There is a lack of clinical research regarding the effect of IDA on white blood cells. However, the clinician should pay attention to such a presentation as it can lead to infection because of lymphocytopenia.

\section{Acknowledgements}

The authors would like to acknowledge the internal medicine residency program for scientific support.

\section{Statement of Ethics}

This case report was approved by the Hamad Medical Corporation's Medical Research Center, and the patient consented to the publication of her case.

\section{Conflict of Interest Statement}

The authors have no conflicts of interest.

\section{Funding Sources}

This work was funded by Qatar National Library.

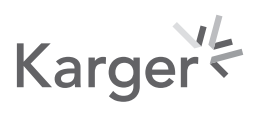




\section{Case Reports in Oncology}

Case Rep Oncol 2020;13:793-797

\begin{tabular}{l|l}
\hline DOI: $10.1159 / 000507823$ & (c) 2020 The Author(s). Published by S. Karger AG, Basel
\end{tabular} www.karger.com/cro

Abdelmahmuod and Yassin: IDA and Lymphocytopenia

\section{Author Contributions}

Both authors contributed equally to writing and editing.

\section{References}

1 Iron deficiency anemia: a common and curable disease [cited 2020 Apr 3]. Available from: https://www.ncbi. nlm.nih.gov/pmc/articles/PMC3685880/.

2 Iron-deficiency anemia - Hematology.org [Internet] [cited 2020 Apr 3]. Available from: https://www.hematology.org/education/patients/anemia/iron-deficiency.

3 Laboratory diagnosis of iron deficiency anemia (IDA) [Internet] [cited 2020 Apr 3]. Available from: http:// laboratorytests.org/laboratory-diagnosis-of-iron-deficiency-anemia-ida/.

4 Causes and diagnosis of iron deficiency and iron deficiency anemia in adults - UpToDate [Internet] [cited 2020 Apr 3]. Available from: https://www.uptodate.com/contents/causes-and-diagnosis-of-iron-deficiency-andiron-deficiency-anemia-in-adults?search=iron deficiency anemia\& source=search_result\& selectedTitle=1 150\&usage_type=default\&display_rank 1 .

5 Jason J, Archibald LK, Nwanyanwu OC, Bell M, Jensen RJ, Gunter E, et al. The effects of iron deficiency on lymphocyte cytokine production and activation: preservation of hepatic iron but not at all cost. Clin Exp Immunol. 2001;126(3):466-73.

6 DuBois S, Kearney DJ. Iron-deficiency anemia and Helicobacter pylori infection: a review of the evidence. Am J Gastroenterol. 2005;100(2):453-9.

7 Chandra RK. Nutrition and the immune system from birth to old age. Eur J Clin Nutr. 2002;56(3):S73-6.

8 Soliman AT, De Sanctis V, Yassin M, Wagdy M, Soliman N. Chronic anemia and thyroid function. Acta Biomed. 2017;88(1):119-27.

9 Soliman AT, De Sanctis V, Yassin M, Adel A. Growth and growth hormone-insulin like growth factor-I (GH-IGF-I) axis in chronic anemias. Acta Biomed. 2017;88(1):101-11.

10 Soliman A, Yassin M, De Sanctis V. Intravenous iron replacement therapy in eugonadal males with iron-deficiency anemia: effects on pituitary gonadal axis and sperm parameters; a pilot study. Indian J Endocrinol Metab. 2014 May;18(3):310-6.

11 Soliman AT, De Sanctis V, Yassin M, Soliman N. Iron deficiency anemia and glucose metabolism. Acta Biomed. 2017;88(1):112-8.

12 Collins HL. The role of iron in infections with intracellular bacteria. Immunol Lett. 2003;85(2):193-5.

\section{Karger ${ }^{\prime}$}

